Supporting Information

\title{
Regulating the Interlayer Spacing of Graphene Oxide Membranes and Enhancing their Stability by use of PACI
}

Ting Liu ${ }^{1,2}$, Long Tian ${ }^{1}$, Nigel Graham ${ }^{2}$, Bing Yang ${ }^{1}$, Wenzheng $\mathrm{Yu}^{3,2 *}$, Kening

$$
\operatorname{Sun}^{1 *}
$$

${ }^{1}$ School of Chemistry and Chemical Engineering, Beijing Institute of Technology, Beijing 100081, China (liuting@bit.edu.cn, keningsunhit@126.com)

${ }^{2}$ Department of Civil and Environmental Engineering, Imperial College London, South Kensington Campus, London SW7 2AZ, UK (n.graham@imperial.ac.uk)

${ }^{3}$ Key Laboratory of Drinking Water Science and Technology, Research Center for Eco-Environmental Sciences, Chinese Academy of Sciences, Beijing 100085, China (w.yu@imperial.ac.uk, wzyu@rcees.ac.cn)

Page S1-S17

Figure S1-S13

Table S1-S2 


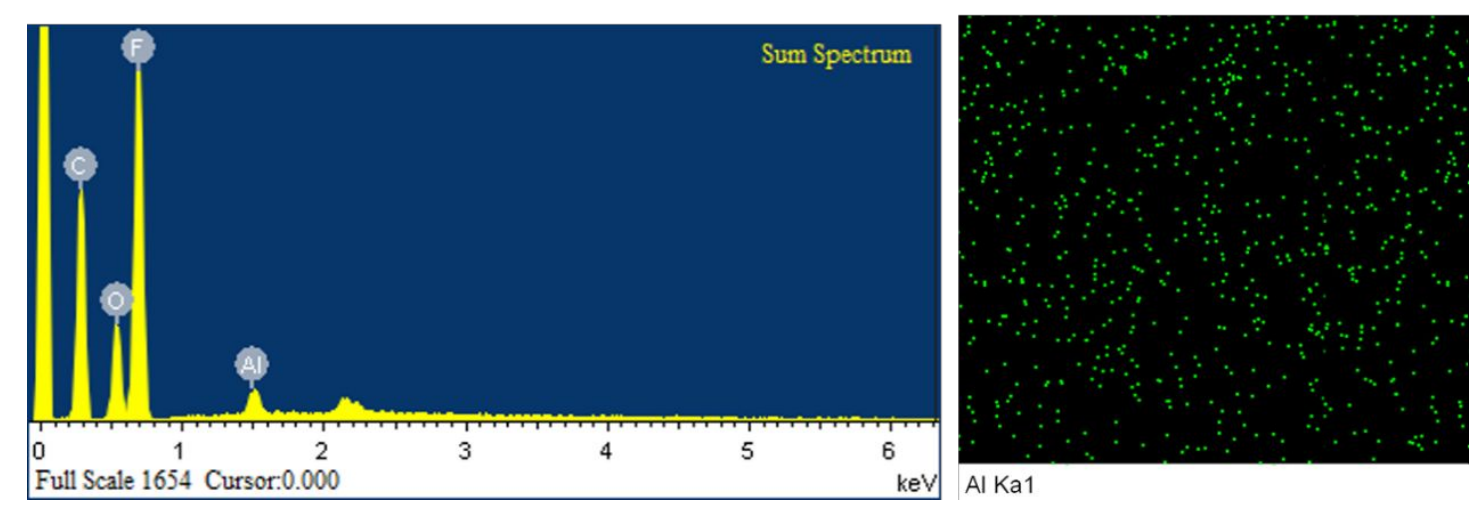

Figure S1. Element analysis and EDX mapping (Al distribution pattern at $5 \mathrm{k} \times$ ) for PACl-GO membrane with $10 \mathrm{mM} \mathrm{PACl}(\mathrm{B}=0)$. 

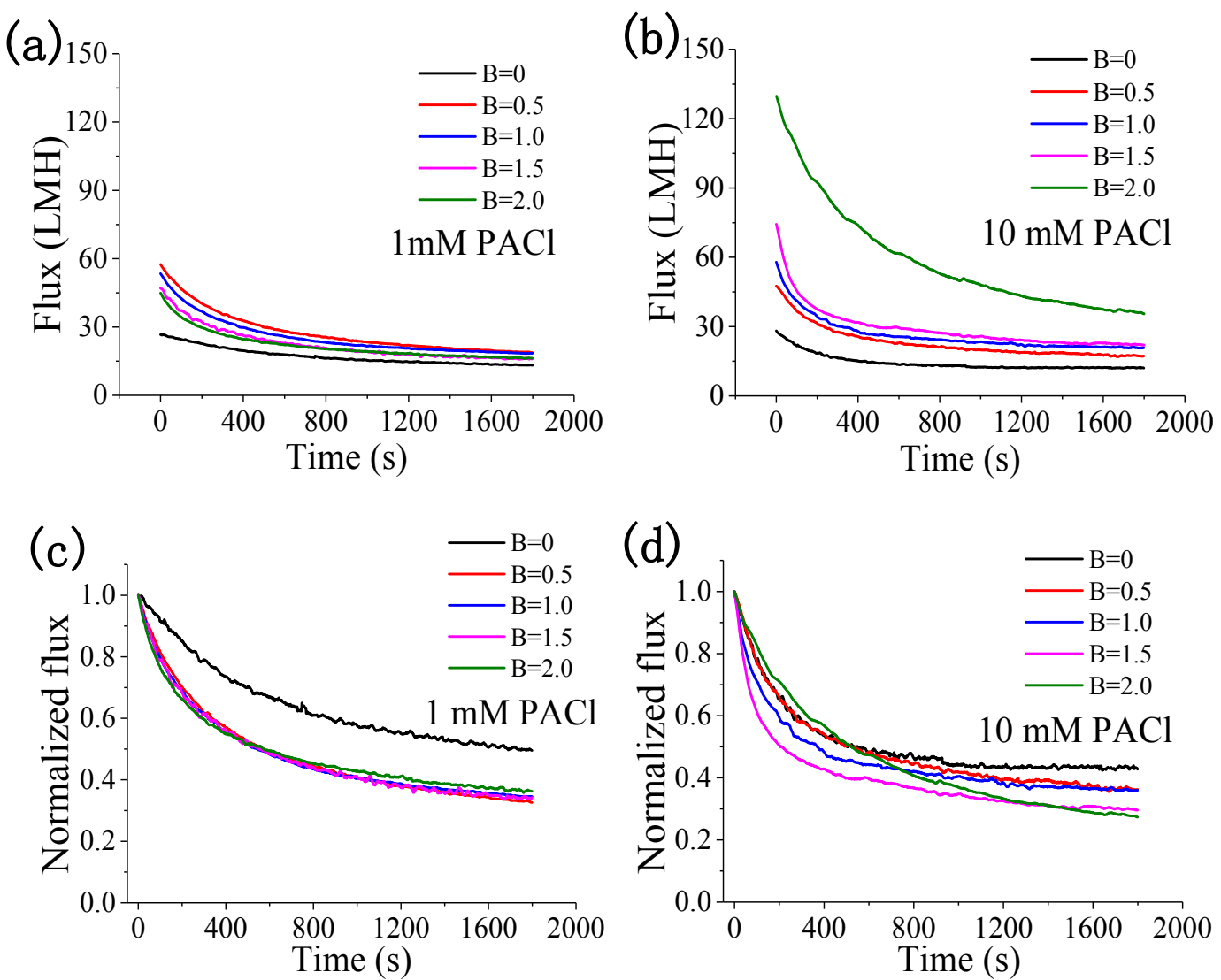

Figure S2. Temporal variation of flux of BSA solution with $\mathrm{PACl}$ concentration and basicity (B): (a) flux for $1 \mathrm{mM}$ PACl-GO membrane, (b) flux for $10 \mathrm{mM}$ PACl-GO membrane, (c) normalized flux for $1 \mathrm{mM}$ PACl-GO membrane, (d) normalized flux for $10 \mathrm{mM}$ PACl-GO membrane. 

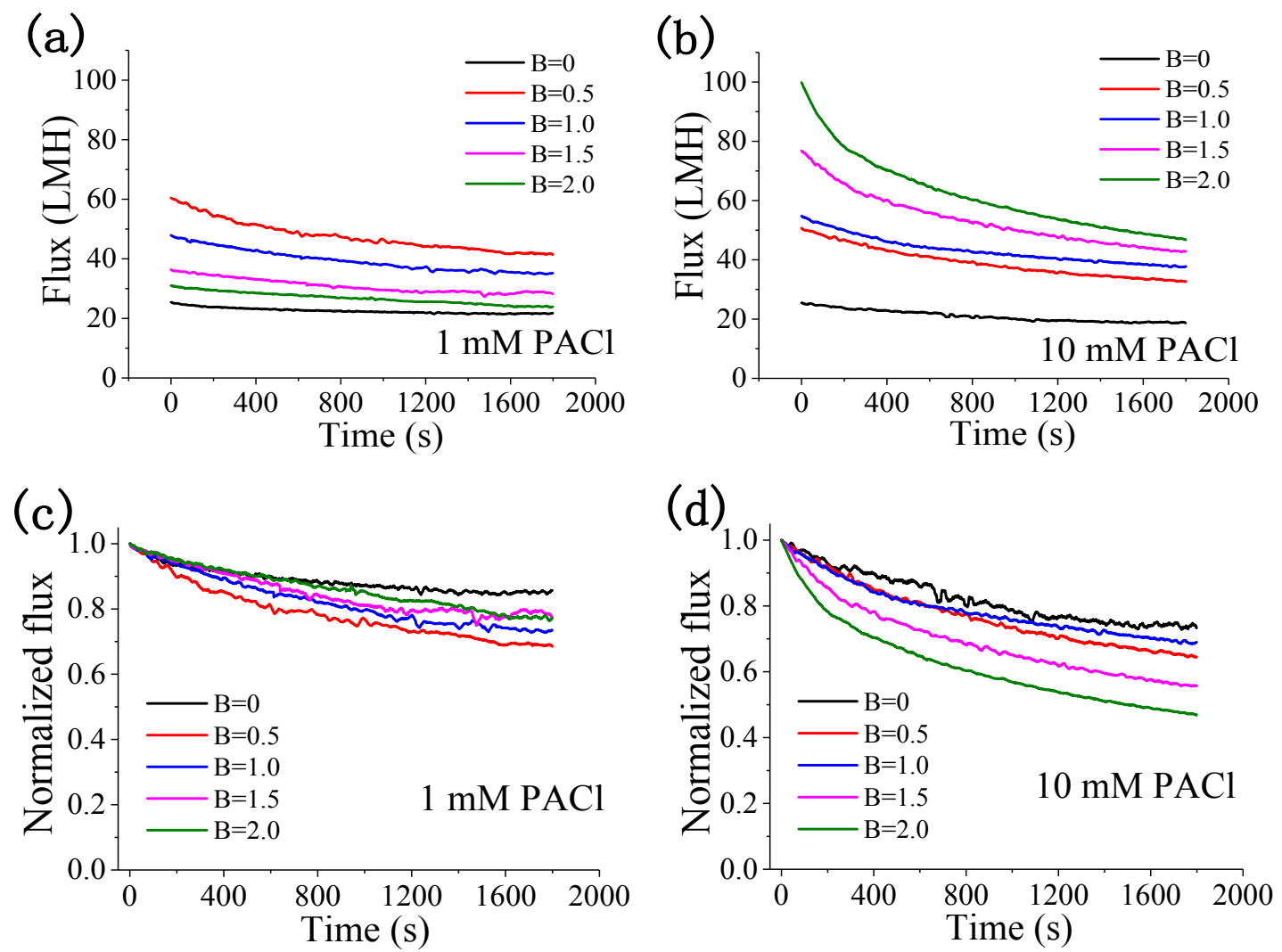

Figure S3. Temporal variation of flux of SA solution with $\mathrm{PACl}$ concentration and basicity (B): (a) flux for $1 \mathrm{mM}$ PACl-GO membrane, (b) flux for $10 \mathrm{mM}$ PACl-GO membrane, (c) normalized flux for $1 \mathrm{mM}$ PACl-GO membrane, (d) normalized flux for $10 \mathrm{mM}$ PACl-GO membrane. 

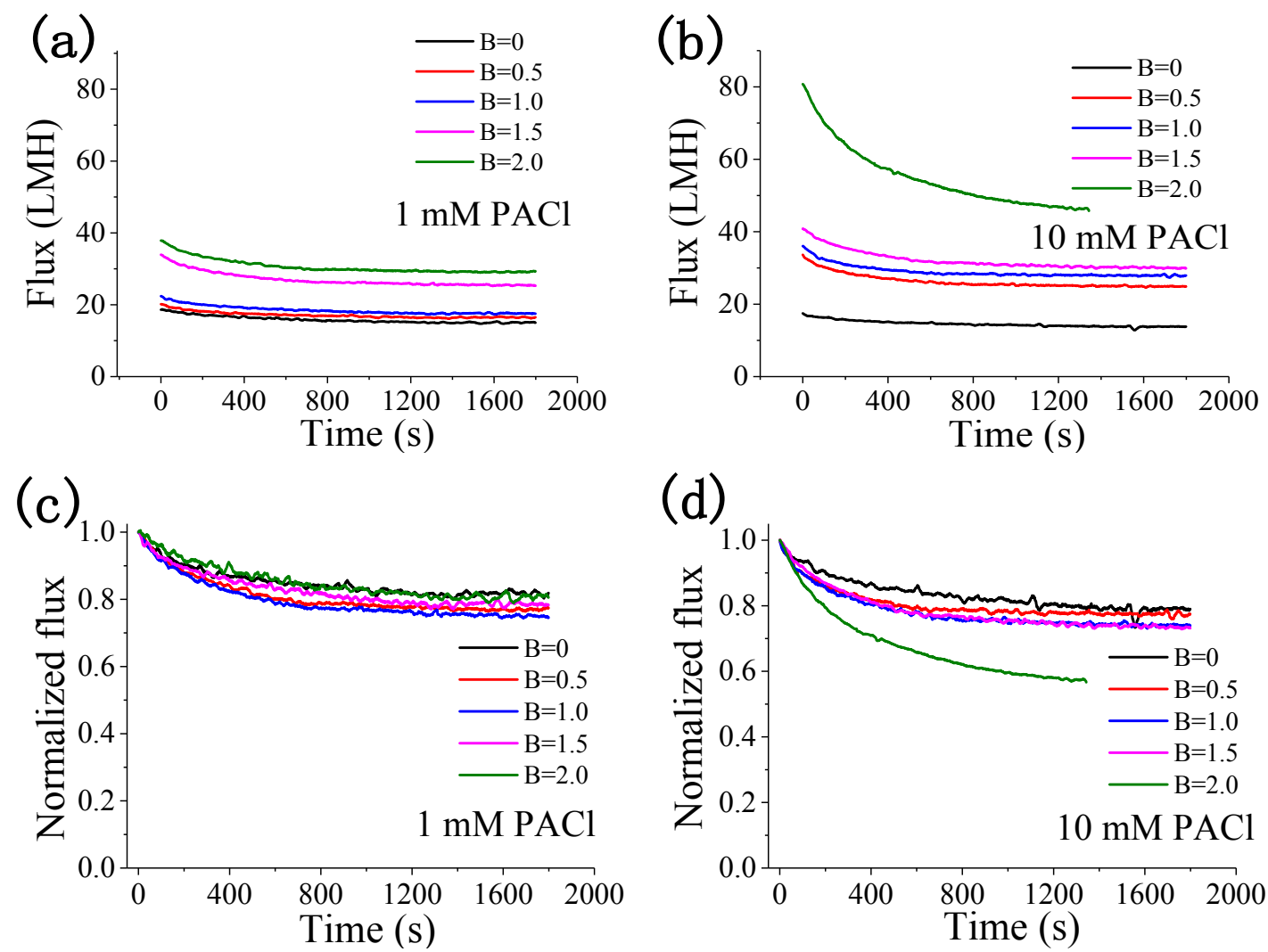

Figure S4. Temporal variation of flux of surface water with $\mathrm{PACl}$ concentration and basicity (B): (a) flux for $1 \mathrm{mM}$ PACl-GO membrane, (b) flux for $10 \mathrm{mM}$ PACl-GO membrane, (c) normalized flux for $1 \mathrm{mM}$ PACl-GO membrane, (d) normalized flux for $10 \mathrm{mM}$ PACl-GO membrane. 

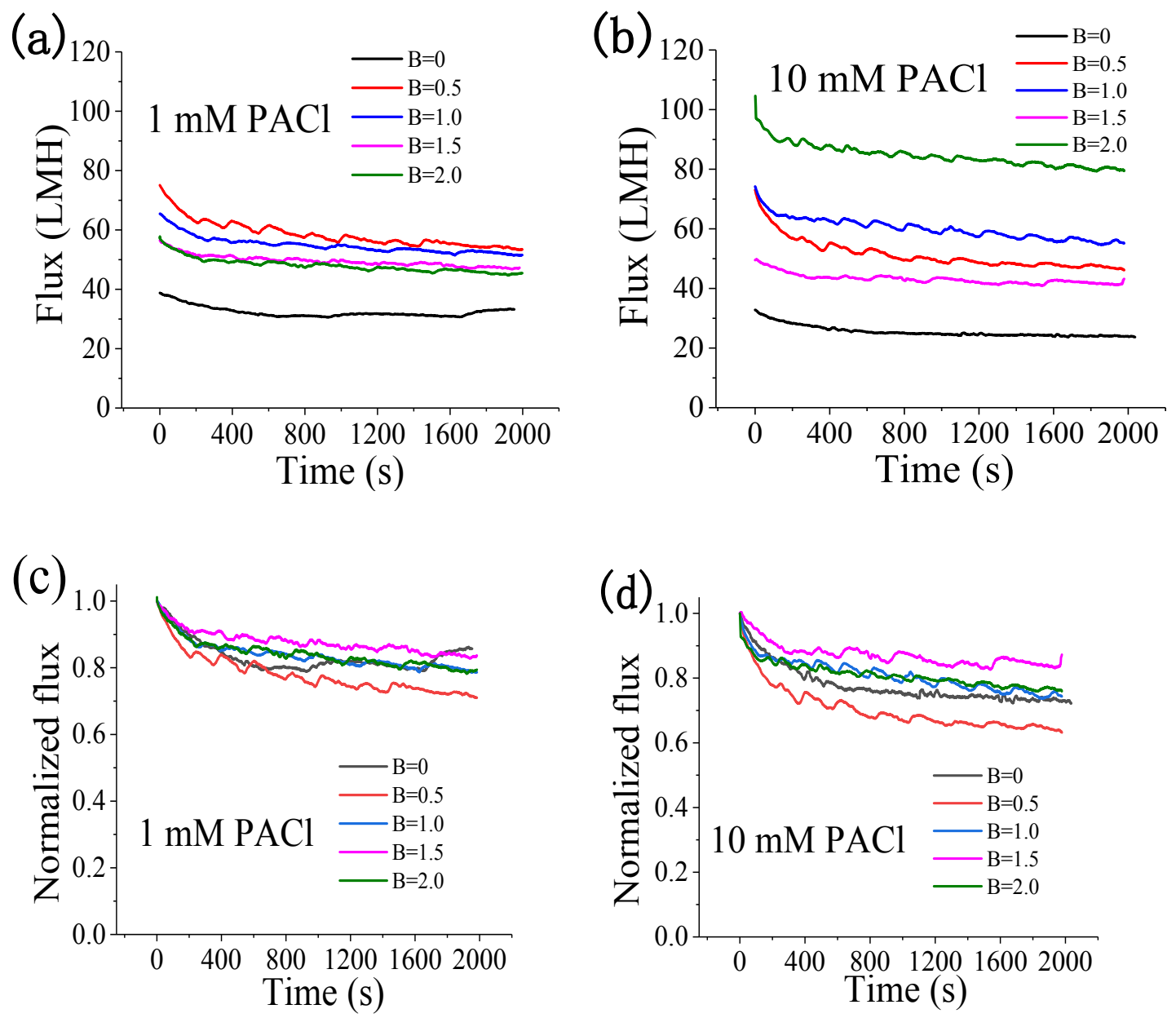

Figure S5. Temporal variation of flux of $\mathrm{HA}$ solution with $\mathrm{PACl}$ concentration and basicity (B): (a) flux for $1 \mathrm{mM}$ PACl-GO membrane, (b) flux for $10 \mathrm{mM}$ PACl-GO membrane, (c) normalized flux for $1 \mathrm{mM}$ PACl-GO membrane, (d) normalized flux for $10 \mathrm{mM}$ PACl-GO membrane. 

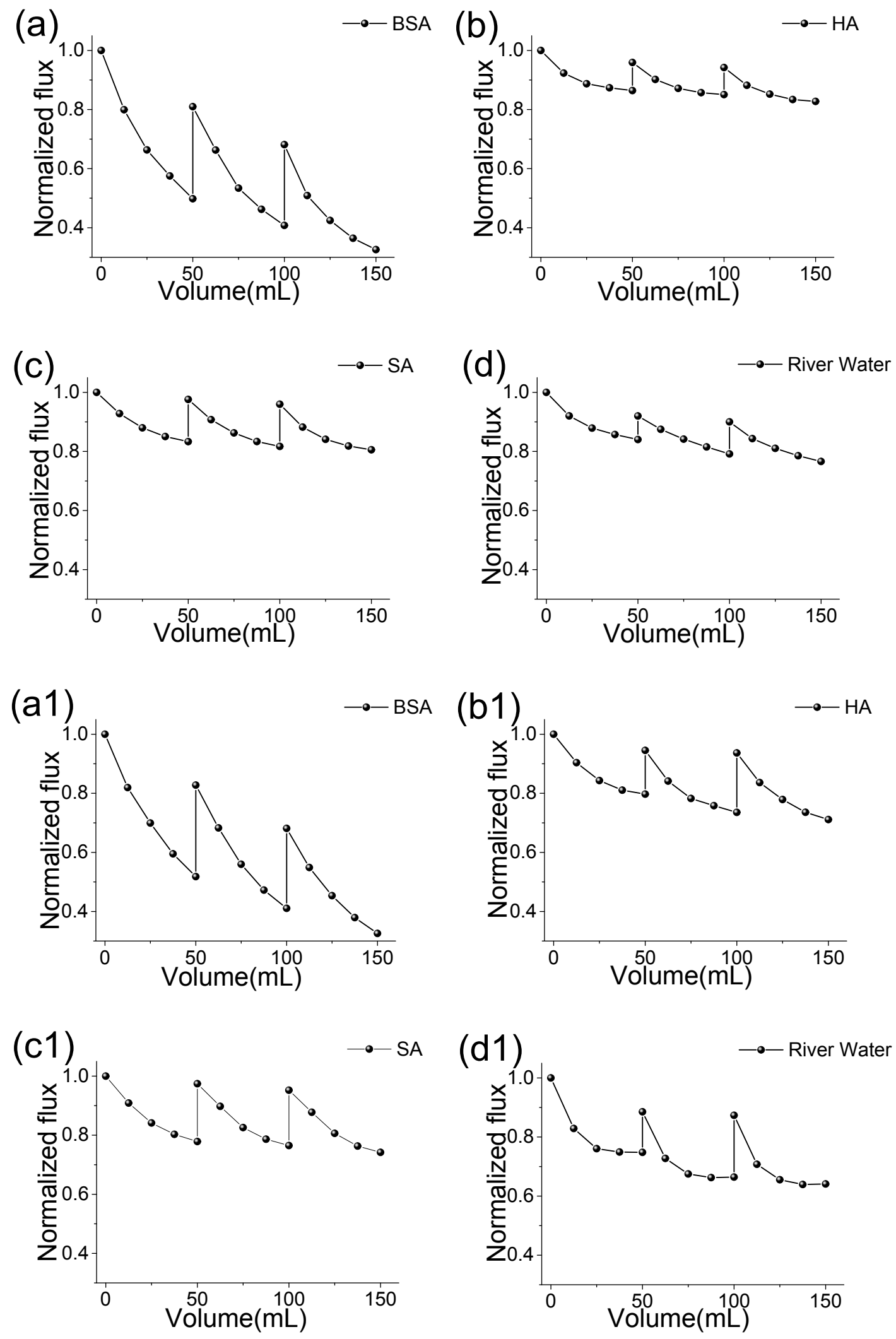

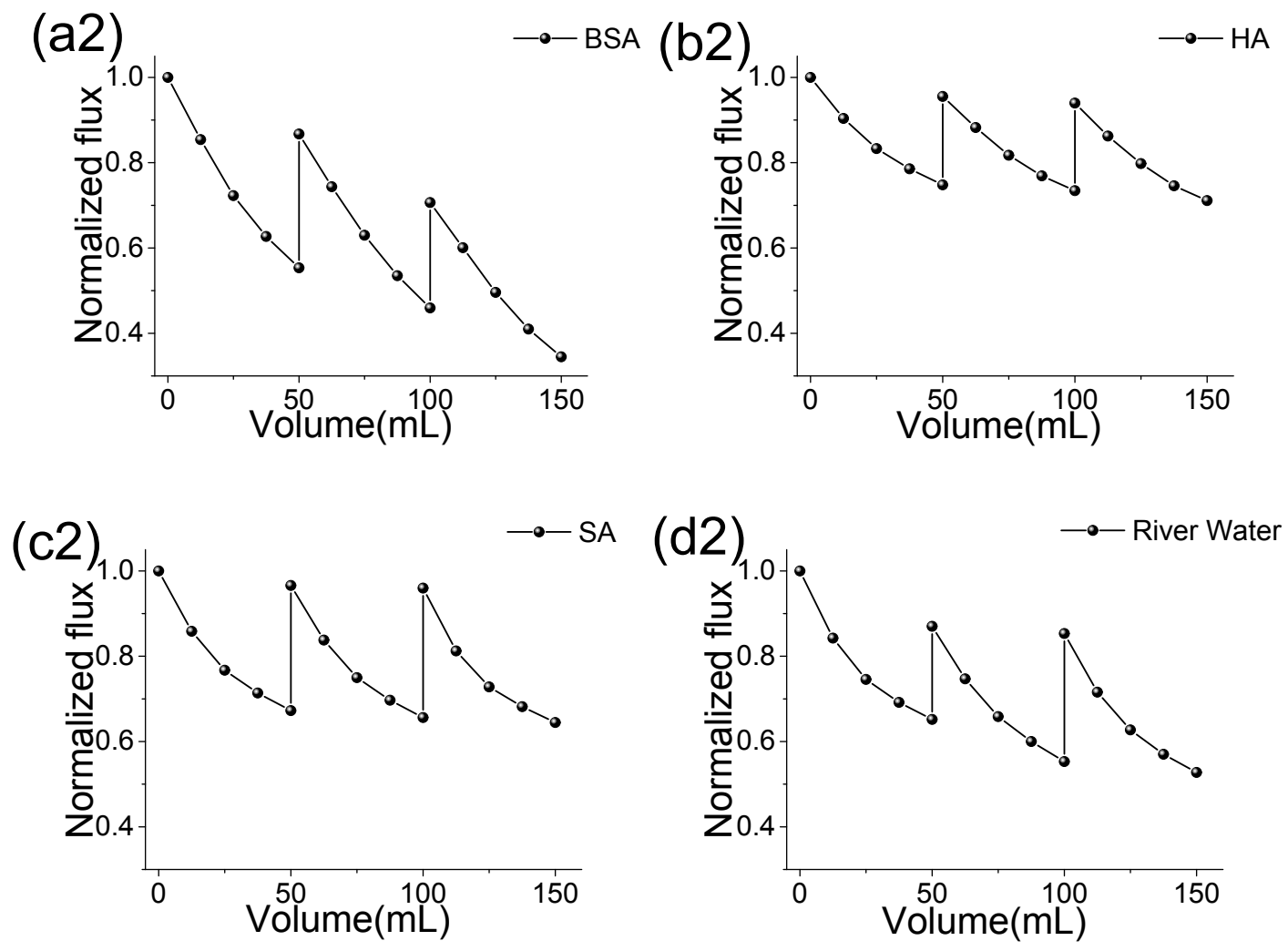

Figure S6. Flux recovery of $\mathrm{B}=0 \mathrm{PACl}-\mathrm{GO}$ membrane $(2 \mathrm{mg}$ GO with $10 \mathrm{mM} \mathrm{PACl})$ for the filtration of BSA (a), HA (b), SA (c) and river water (d). Flux recovery of $\mathrm{B}=1.0$ PACl-GO membrane ( $2 \mathrm{mg}$ GO with $10 \mathrm{mM} \mathrm{PACl}$ ) for the filtration of BSA (a1), HA (b1), SA (c1) and river water (d1). Flux recovery of B=2.0 PACl-GO membrane (2 mg GO with $10 \mathrm{mM} \mathrm{PACl}$ ) for the filtration of BSA (a2), HA (b2), SA (c2) and river water (d2). 
(a)

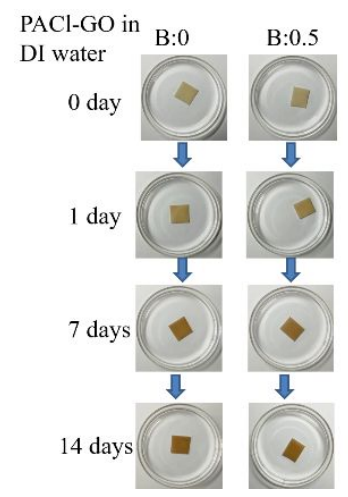

(c)

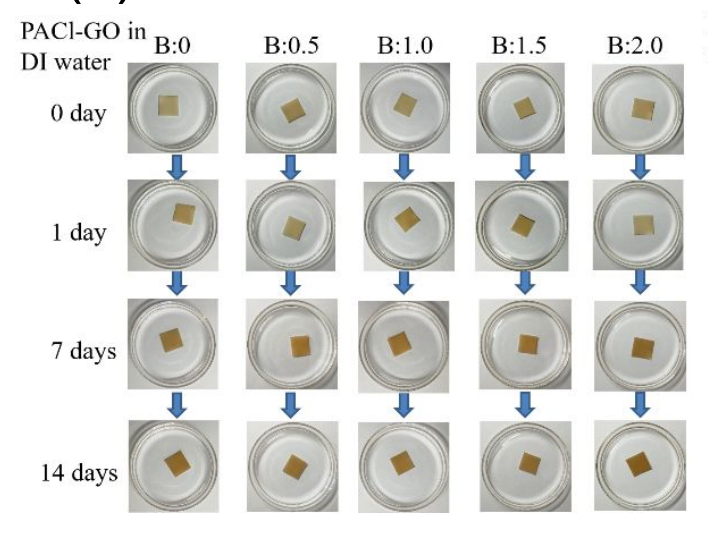

(b)

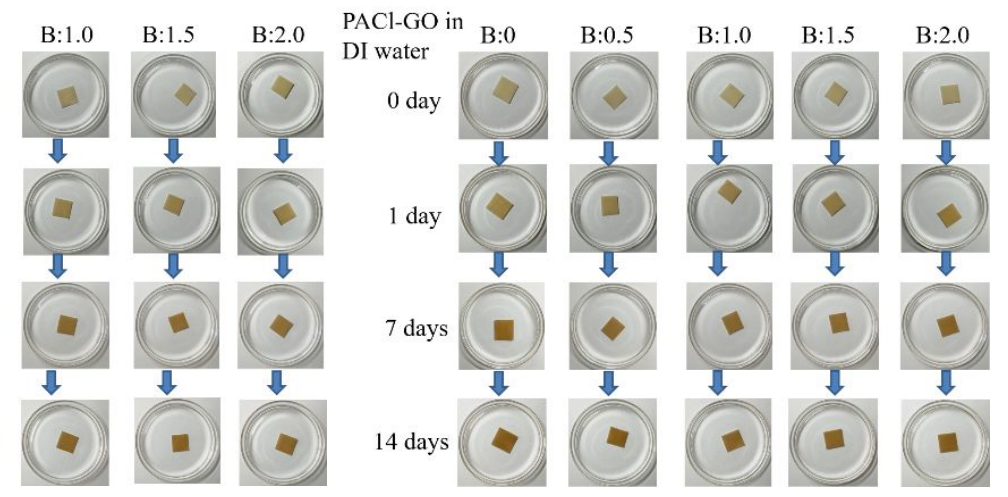

(d)

$\begin{array}{llll}\text { PACl-GO in } & \text { B:0 B:0.5 B: } 1.0 \quad \text { B: } 1.5 \quad \text { B:2.0 } \\ \text { DI water } & \end{array}$

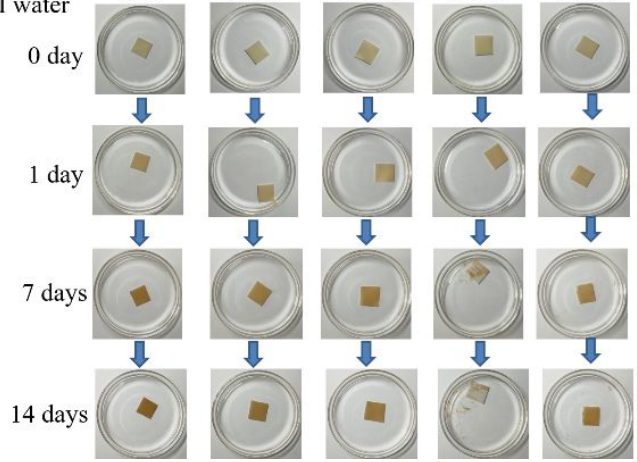

Figure S7. Variation of PACl-GO membrane stability in DI water with basicity and concentration of PACl: $10 \mathrm{mM}$ (a); $1 \mathrm{mM}$ (b); $0.1 \mathrm{mM}$ (c); $0.05 \mathrm{mM}$ (d). 
(a)

$\mathrm{PACl}-\mathrm{GO}$ in $1 \mathrm{M}$
$\mathrm{NaCl}$ solution

0 day

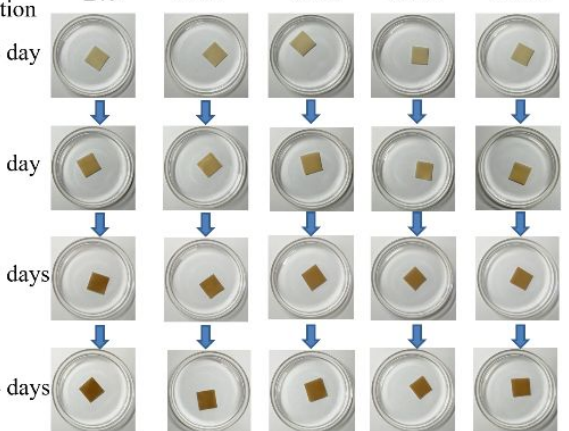

(c)

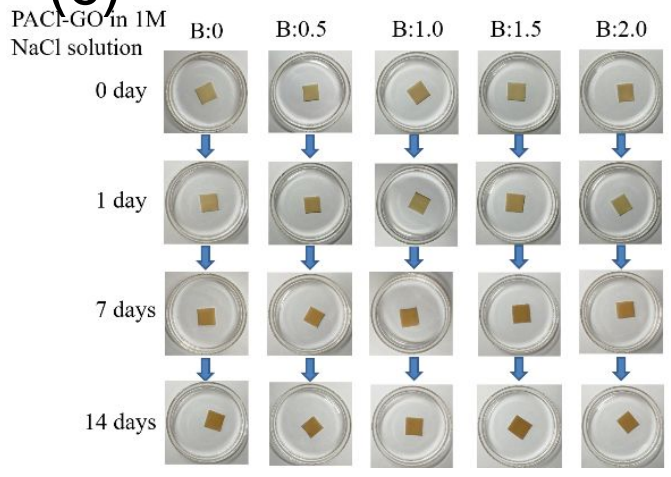

(b)

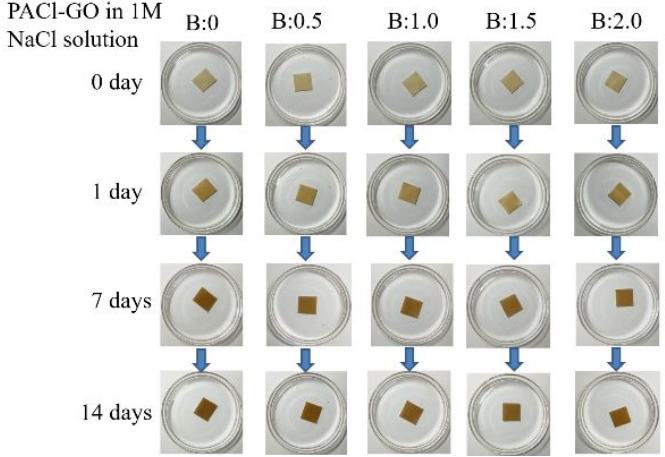

(d)

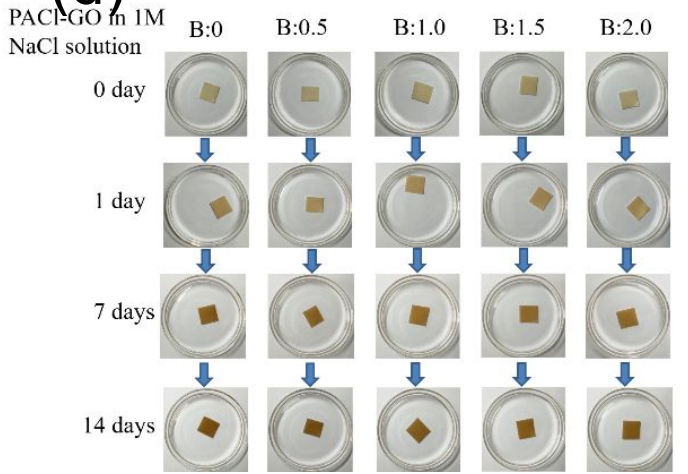

Figure S8. Variation of PACl-GO membrane stability in $1 \mathrm{M} \mathrm{NaCl}$ solution with basicity and concentration of PACl: $10 \mathrm{mM}$ (a); $1 \mathrm{mM}$ (b); $0.1 \mathrm{mM}$ (c); $0.05 \mathrm{mM}$ (d). 


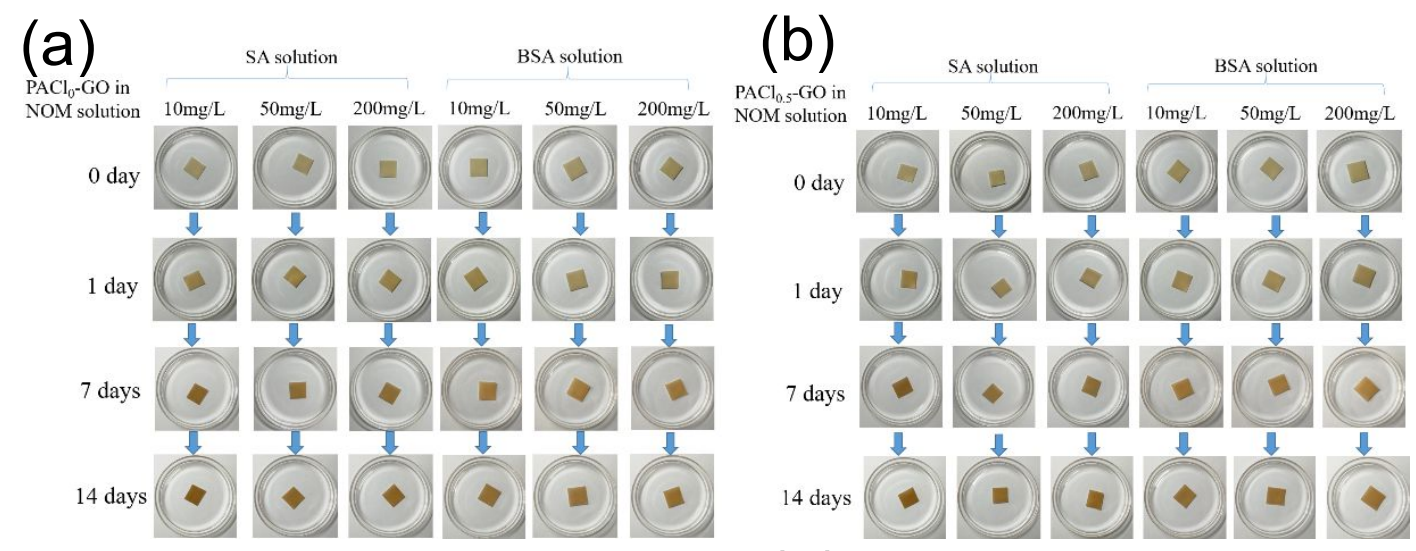

(c)

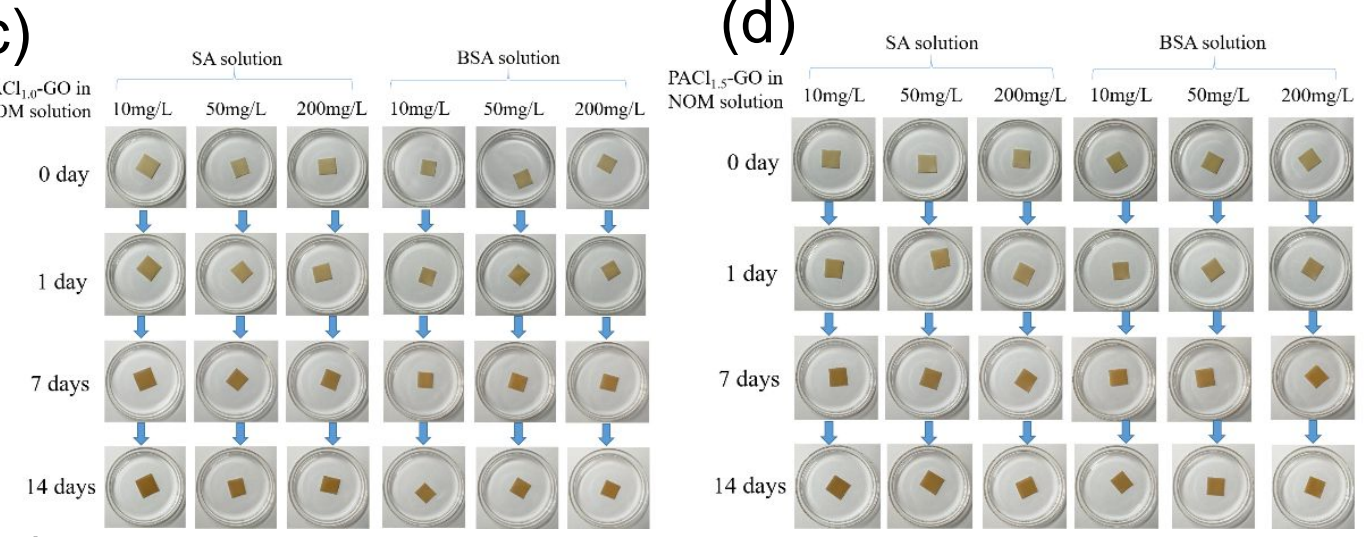

(e)

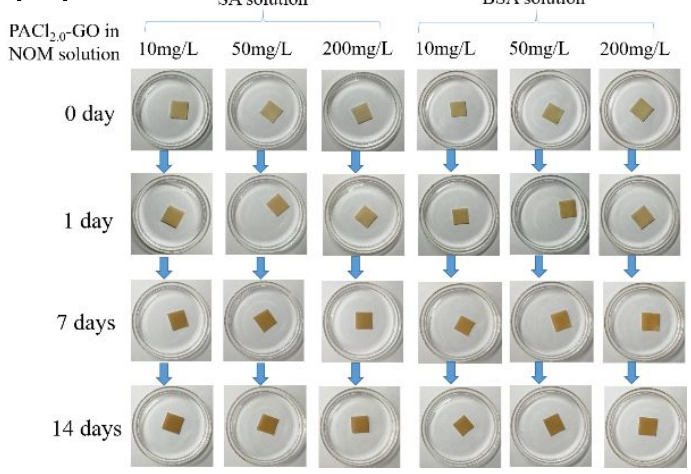

Figure S9. Variation of PACl-GO membrane stability (10 mM PACl) in SA and BSA solutions with NOM concentration and B value: 0 (a), 0.5(b), 1.0 (c), 1.5 (d), 2.0(e). 
(a)

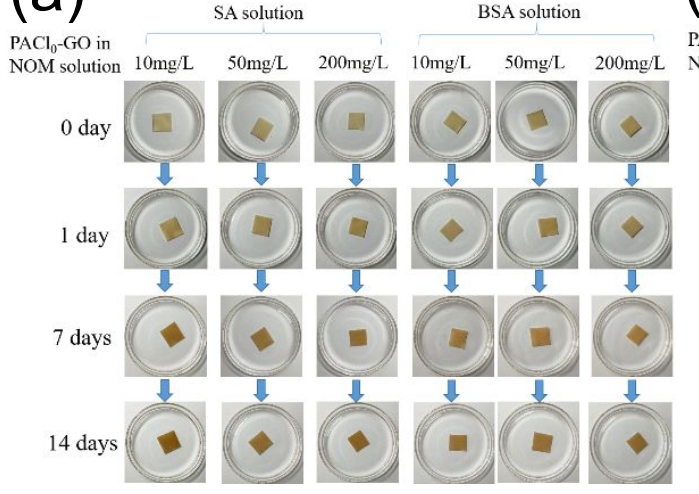

(c)

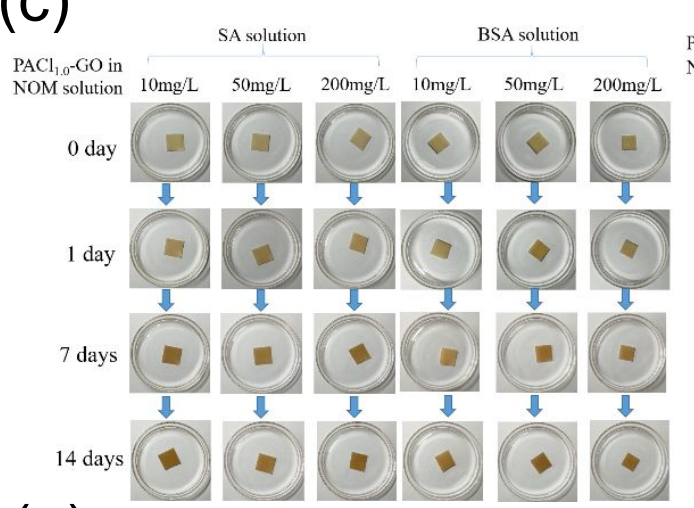

(e)

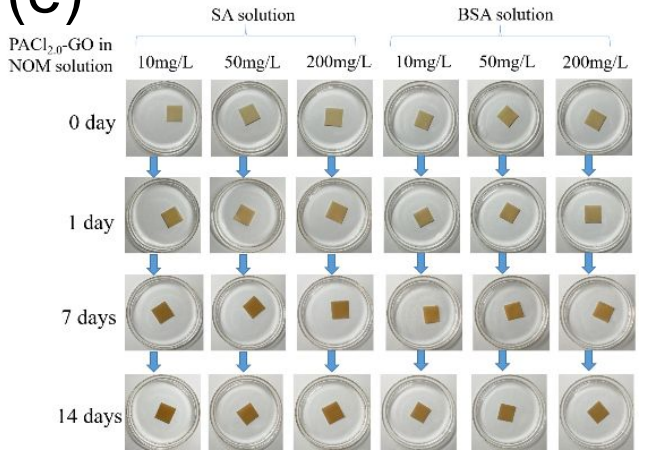

(b)

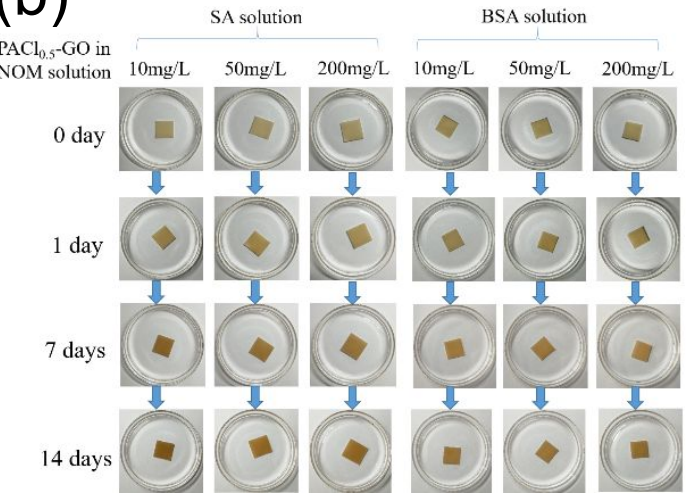

(d)

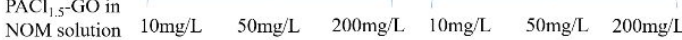

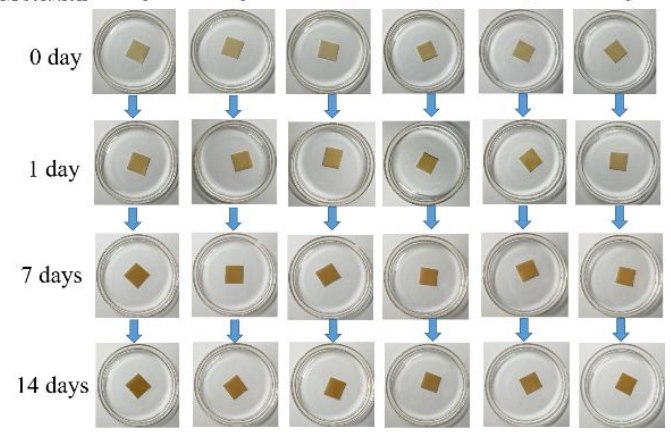

Figure S10. Variation of PACl-GO membrane stability (1 mM PACl) in SA and BSA solutions with NOM concentration and B value: 0 (a), 0.5(b), 1.0 (c), 1.5 (d), 2.0(e). 
(a)

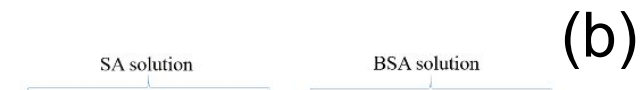

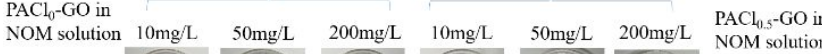

0 day

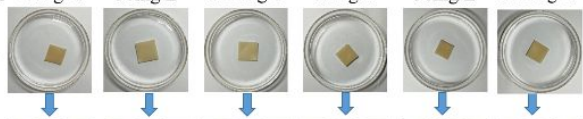

day
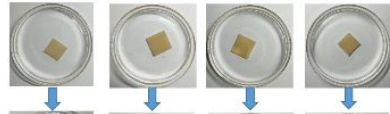

7 days

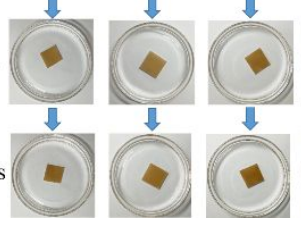

(c)
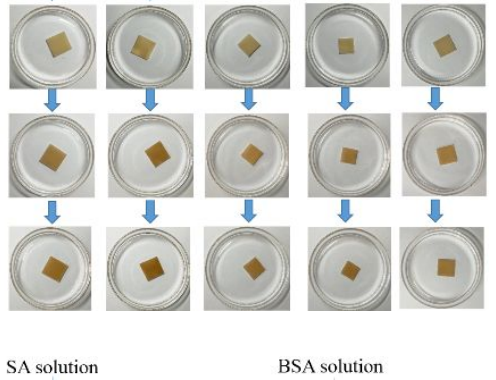

BSA solution

\section{(d)}

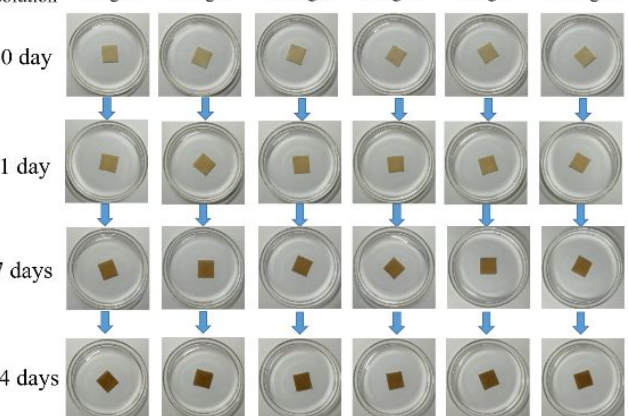

d) SA solution BSA solution

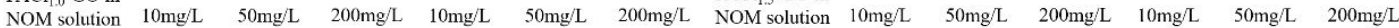

day

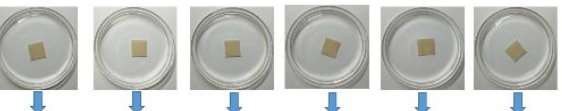

1 day

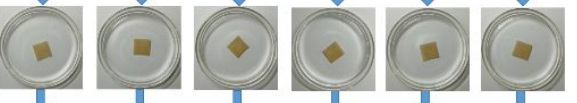

7 days
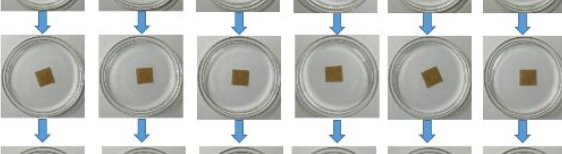

14 days
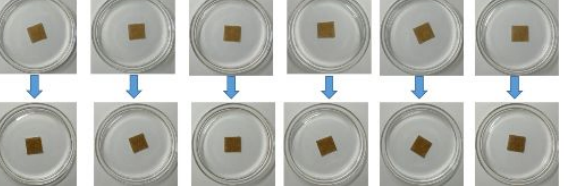

0 day

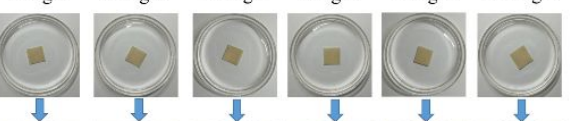

1 day
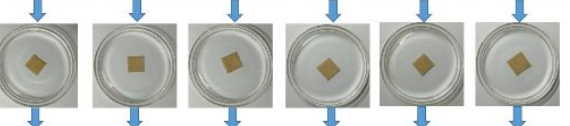

(e)

SA solution
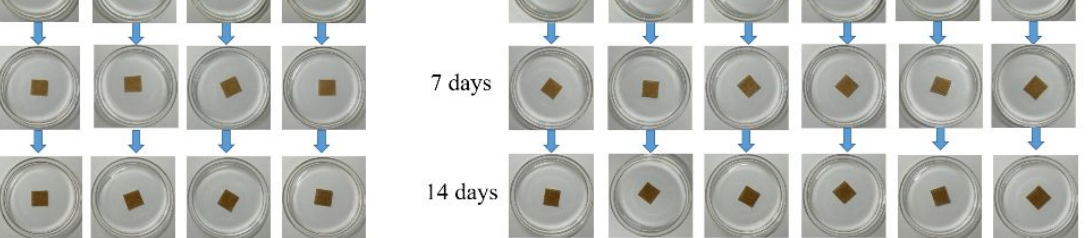

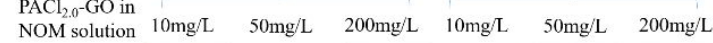

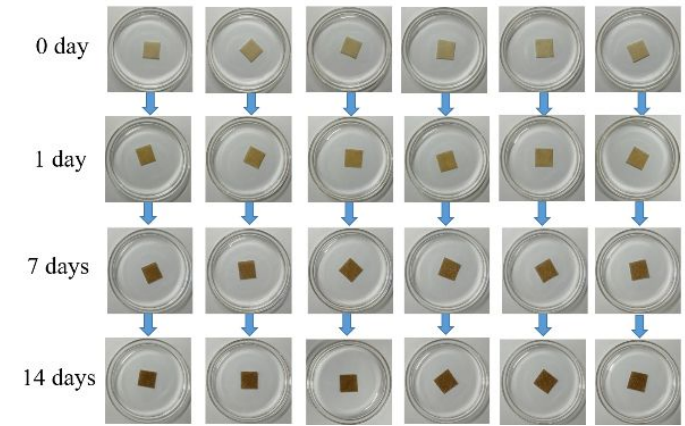

Figure S11. Variation of PACl-GO membrane stability $(0.1 \mathrm{mM} \mathrm{PACl})$ in SA and BSA solutions with NOM concentration and B value: 0 (a), 0.5(b), 1.0 (c), 1.5 (d), 2.0(e). 
(a)

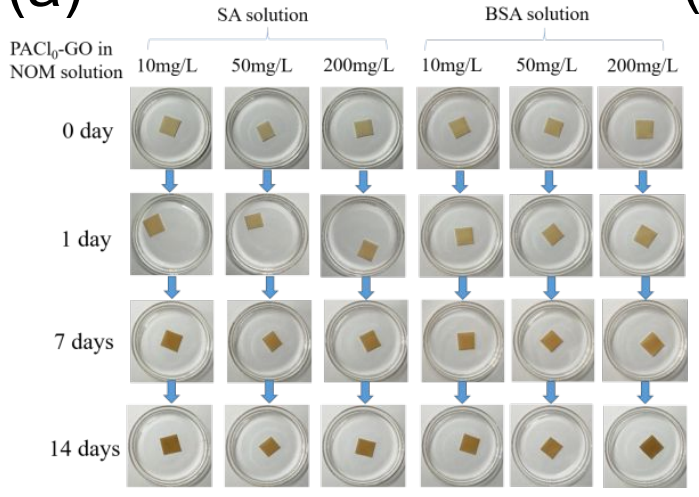

(c)

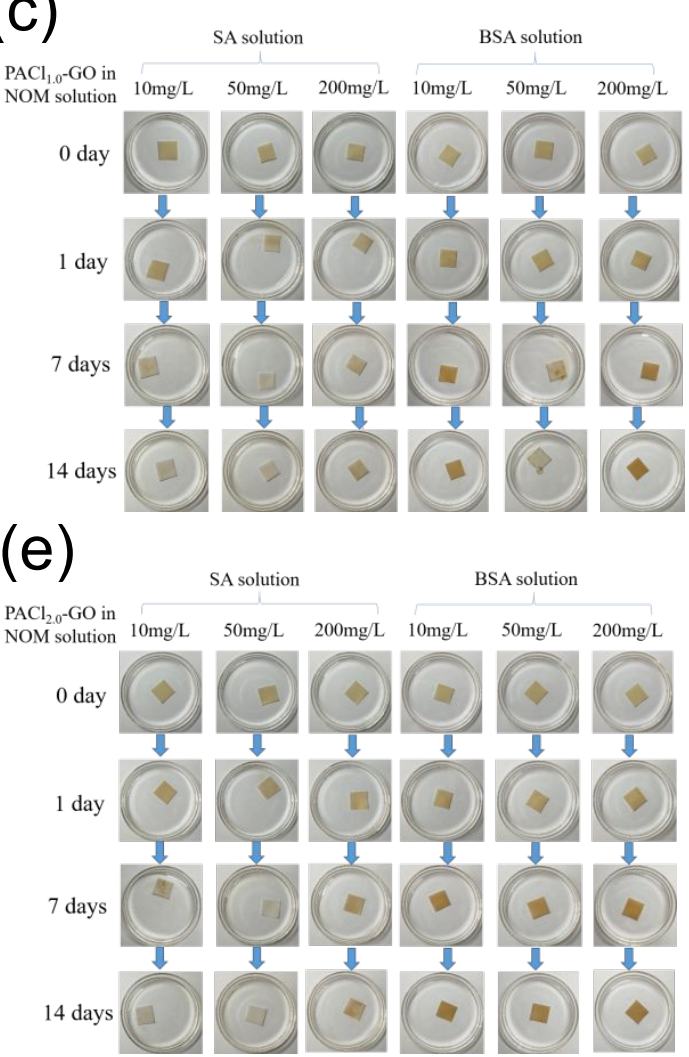

(b)

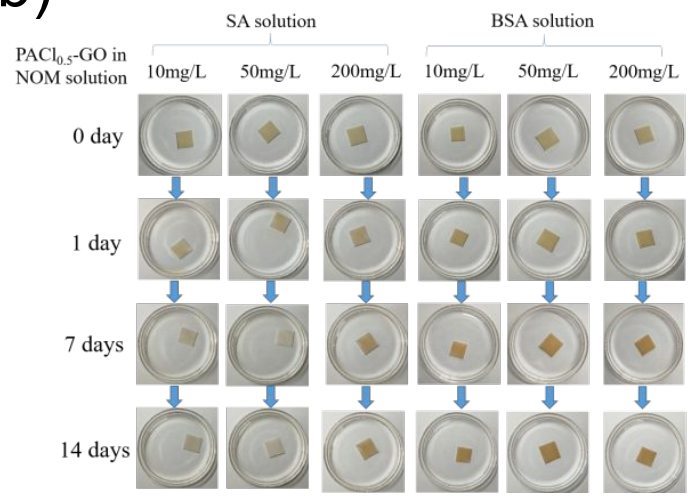

(d)

SA solution

BSA solution

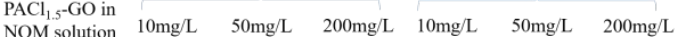

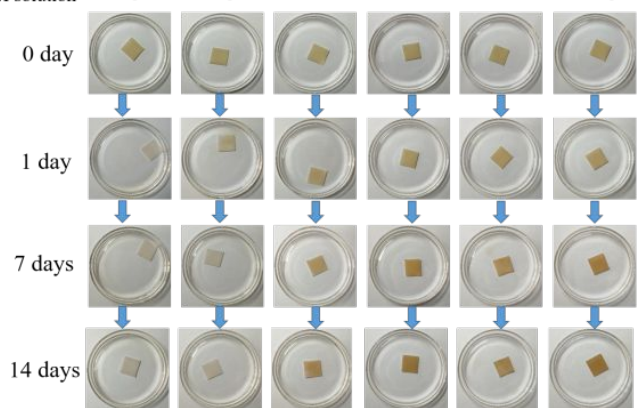

Figure S12. Variation of PACl-GO membrane stability $(0.05 \mathrm{mM} \mathrm{PACl})$ in SA and BSA solutions with NOM concentration and B value: 0 (a), 0.5(b), 1.0 (c), 1.5 (d), 2.0(e). 

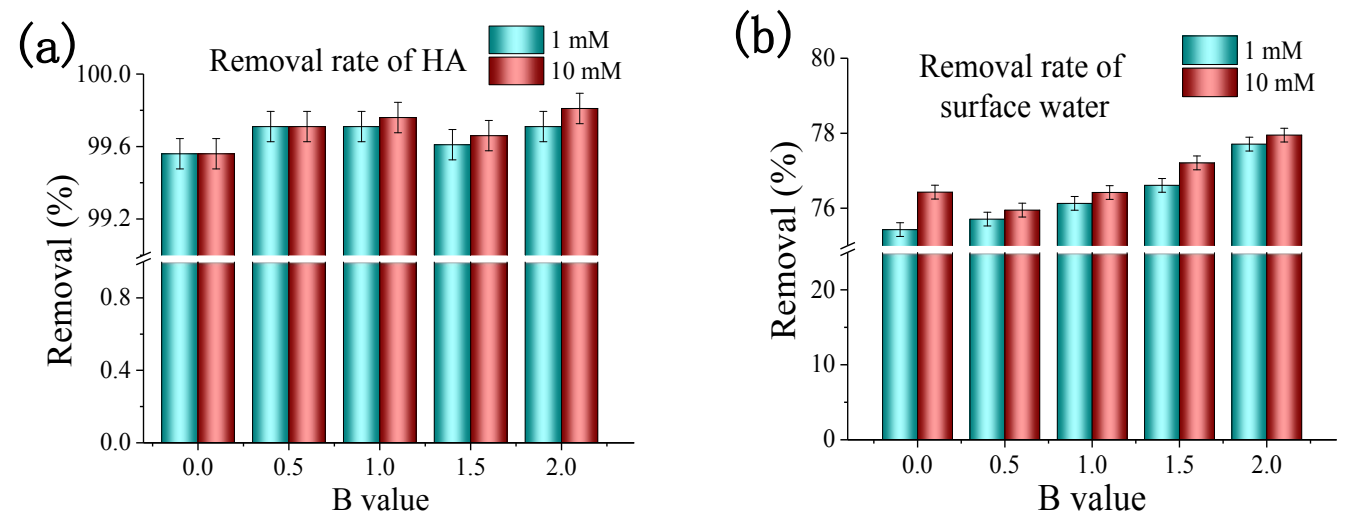

Figure S13. Variation of NOM removal (\% change in $\mathrm{UV}_{254}$ ) for HA solution (a) and surface water (b) by PACl-GO membrane with $\mathrm{PACl}$ concentration and $\mathrm{B}$ value. 
Table S1. Representative water quality parameters and values of South Long River, Beijing, China

\begin{tabular}{cccccc}
\hline $\begin{array}{c}\text { TOC } \\
(\mathrm{mg} / \mathrm{L})\end{array}$ & $\begin{array}{c}\mathrm{UV}_{254}-\mathrm{abs} \\
\left(\mathrm{cm}^{-1}\right)\end{array}$ & SUVA & $\mathrm{pH}$ & $\begin{array}{c}\text { Cond } \\
(\mu \mathrm{S} / \mathrm{cm})\end{array}$ & $\begin{array}{c}\text { Zeta Potential } \\
(\mathrm{mV})\end{array}$ \\
\hline $4.14 \pm 0.25$ & $0.113 \pm 0.006$ & $2.730 \pm 0.14$ & $7.98 \pm 0.12$ & $233.7 \pm 6.9$ & $-3.46 \pm 0.34$ \\
\hline
\end{tabular}


Table S2. Flux recovery ratio (FRR\%), reversible fouling (\%) and irreversible fouling (\%) of the membranes in the first filtration cycle

\begin{tabular}{cccccc}
\hline $\begin{array}{c}\text { Membrane } \\
(10 \mathrm{mM} \mathrm{PACl}, \\
2 \mathrm{mg} \mathrm{GO})\end{array}$ & $\%$ & BSA & HA & SA & $\begin{array}{c}\text { Surface } \\
\text { water }\end{array}$ \\
\hline \multirow{2}{*}{ PACl $_{0}$-GO } & FRR & 81.0 & 95.9 & 97.6 & 92.7 \\
membrane & Reversible & 62.1 & 70.0 & 85.5 & 49.9 \\
& Irreversible & 37.9 & 30.0 & 14.5 & 50.1 \\
PACl $_{1.0}$-GO & FRR & 82.7 & 96.7 & 98.1 & 92.3 \\
membrane & Reversible & 64.3 & 76.2 & 88.4 & 54.5 \\
& Irreversible & 35.7 & 23.8 & 11.6 & 45.5 \\
PACl $_{2.0}-\mathrm{GO}$ & FRR & 86.7 & 95.5 & 98.9 & 87.6 \\
membrane & Reversible & 70.3 & 82.2 & 92.6 & 62.7 \\
& Irreversible & 29.7 & 17.8 & 7.4 & 37.3 \\
\hline
\end{tabular}

